\title{
'Papaya Seed' Appearance of Subependymal Nodules on Magnetic Resonance Imaging in a Patient with Tuberous Sclerosis
}

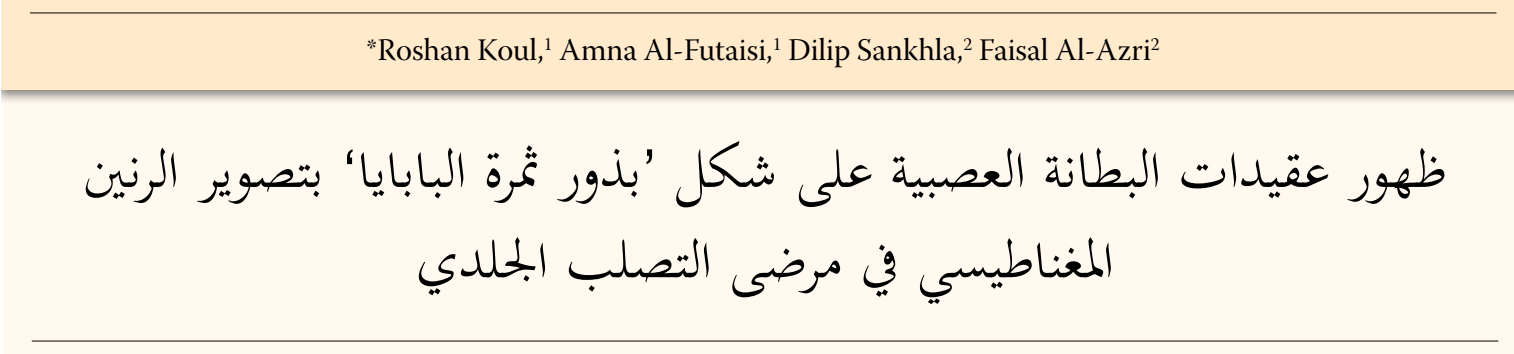

روشان كول، آمنة الفطيسية، ديليب سانخلا، فيصل العزري
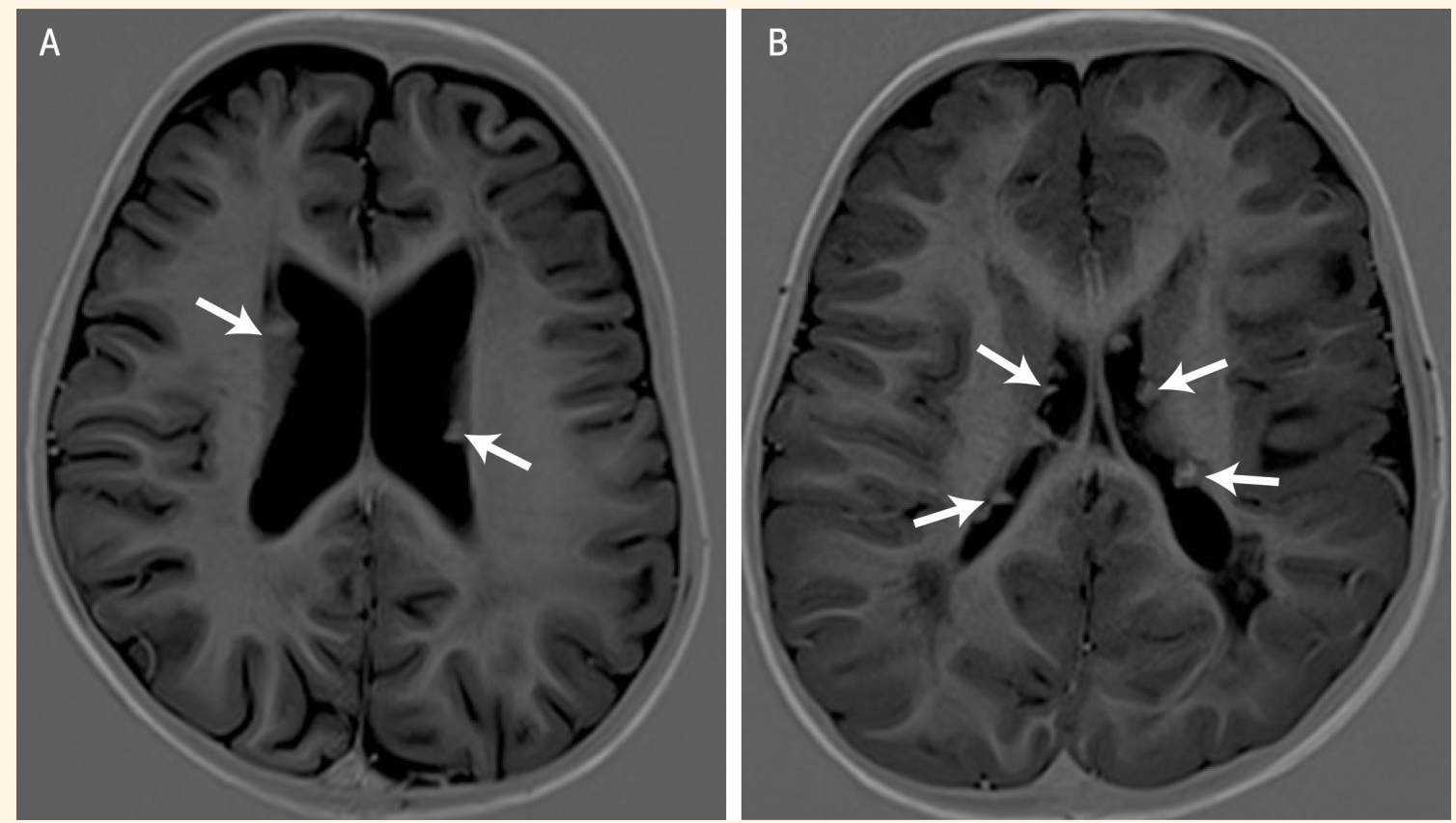

Figure 1A \& B: T1-weighted axial magnetic resonance images showing subependymal nodules (arrows) with a 'papaya seed' appearance in two patients with tuberous sclerosis.

A 14-MONTH-OLD MALE WAS REFERRED TO the Department of Child Health at the Sultan Qaboos University Hospital (SQUH), Muscat, Oman, in 2014 with a two-week history of frequent abnormal movements of the body. A video, recorded by the patient's father, revealed that the patient suffered from typical flexor body spasms and left side partial motor seizures. On physical examination, the patient had several cutaneous features of tuberous sclerosis, including depigmented skin lesions and Shagreen patches. A neurological examination was unremarkable. Sleep electroencephalography displayed interictal generalised and focal discharges from the left frontocentral region. There was no evidence of hypsarrhythmia. Magnetic resonance imaging (MRI) of the brain revealed multifocal cortical and subcortical tubers with subependymal nodules (SEN) which had a 'papaya seed' appearance [Figure 1A]. Four to five rhabdomyomas in both ventricles were visible on echocardiography. Ophthalmological examination revealed an astrocytoma along the inferior vascular arcade close to the optic nerve of the left eye. The 
patient's father had a possible skin lesion on his back, while the rest of the family had normal examinations. The child was diagnosed with tuberous sclerosis and epilepsy. He was initially prescribed the antiepileptic medication vigabatrin; due to a lack of response, this was changed to topiramate and levetiracetam after two weeks.

\section{Comment}

Tuberous sclerosis is a neurocutaneous disease characterised by skin lesions, often in association with epilepsy (80-90\% of cases) and mental retardation (40-70\% of cases). ${ }^{1,2}$ The disease may affect any organ of the body, but predominantly involves the brain. The diagnostic criteria of tuberous sclerosis have recently been revised with the new criteria emphasising clinical elements of the disease based on 11 major and nine minor features. ${ }^{3}$ For a diagnosis of definite tuberous sclerosis, evidence of two major features or one major feature with two or more minor features is essential. The presence of one major feature or two minor features is labelled as possible tuberous sclerosis. ${ }^{3}$ Subependymal giant cell astrocytoma and SEN are considered two major features; the latter are seen in $80 \%$ of patients with tuberous sclerosis and can be detected antenatally or at birth. ${ }^{4}$ These benign growths develop along the ependymal lining of the lateral and third ventricles.

Computed tomography $(\mathrm{CT})$ of the brain allows easy visualisation of SEN due to calcification. ${ }^{5}$ An MRI scan alone can easily miss calcific lesions and hence a CT scan is also often performed to confirm the calcification. ${ }^{6}$ At SQUH, analysis of CT and MRI scans performed on children with tuberous sclerosis has shown that MRI imaging of multiple SEN attached to the ventricular wall closely resemble papaya seeds attached to the interior of the fruit [Figure 1B]. Observations of clinical features of tuberous sclerosis combined with the 'papaya seed' appearance of SEN on an MRI scan could obviate the need for additional $\mathrm{CT}$ imaging among patients with tuberous sclerosis.

\section{References}

1. Holmes GL, Stafstrom CE; Tuberous Sclerosis Study Group. Tuberous sclerosis complex and epilepsy: Recent developments and future challenges. Epilepsia 2007; 48:617-30. doi: 10.11 11/j.1528-1167.2007.01035.x.

2. Jóźwiak S, Kotulska K, Domańska-Pakieła D, Lojszczyk B, Syczewska M, Chmielewski D, et al. Antiepileptic treatment before the onset of seizures reduces epilepsy severity and risk of mental retardation in infants with tuberous sclerosis complex. Eur J Paediatr Neurol 2011; 15:424-31. doi: 10.1016/j. ejpn.2011.03.010

3. Northrup H, Krueger DA; International Tuberous Sclerosis Complex Consensus Group. Tuberous sclerosis complex diagnostic criteria update: Recommendations of the 2012 International Tuberous Sclerosis Complex Consensus Conference. Pediatr Neurol 2013; 49:243-54. doi: 10.1016/j. pediatrneurol.2013.08.001.

4. Crino PB, Mehta R, Vinters HV. Pathogenesis of TSC in the brain. In: Kwiatkowsi DJ, Whittermore VH, Thiele EA, Eds. Tuberous Sclerosis Complex: Genes, clinical features and therapeutics. Weinheim, Germany: Wiley-Blackwell, 2010. Pp. 161-86.

5. Pinto Gama HP, da Rocha AJ, Braga FT, da Silva CJ, Maia AC Jr, de Campos Meirelles RG, et al. Comparative analysis of MR sequences to detect structural brain lesions in tuberous sclerosis. Pediatr Radiol 2006; 36:119-25. doi: 10.1007/s00247005-0033-x.

6. Avrahami E, Cohn DF, Feibel M, Tadmor R. MRI demonstration and CT correlation of the brain in patients with idiopathic intracerebral calcifications. J Neurol 1994; 241:381-4. doi: 10.1007/BF02033355. 